\title{
DUPLICATION OF INFERIOR VENA CAVA AND CONTINUATION OF LEFT INFERIOR VENA CAVA AS AZYGOS VEIN: A CASE REPORT
}

\author{
Parveen Ojha' ${ }^{1}$, Seema Prakash ${ }^{2}$, L.K. Jain ${ }^{3}$
}

\section{HOW TO CITE THIS ARTICLE:}

Parveen Ojha, Seema Prakash, L. K. Jain. "Duplication of Inferior Vena Cava and Continuation of Left Inferior Vena Cava as Azygos Vein: A Case Report". Journal of Evolution of Medical and Dental Sciences 2013; Vol2, Issue 29, July 22; Page: 5317-5322.

ABSTRACT: A rare variant of duplication of inferior vena cava was observed during routine dissection of posterior abdominal wall of a middle aged cadaver. During dissection of the thorax, a large diameter vena azygos was noticed. After completion of thorax dissection, the thoracic cage was removed by cutting at $7^{\text {th }}$ thoracic vertebra .During dissection of the abdomen two Inferior Vena Cava, Right and Left were observed .Right and left inferior vena cava were seen arising from an inter-iliac venous channel present transversely in front of the body of $4^{\text {th }}$ lumbar vertebra. Right inferior vena cava followed its normal course through the liver to the right atrium, while left inferior vena cava after its formation received left renal vein, behaved like hemiazygos vein as it passed behind aorta, then through the aortic opening of diaphragm ascended as vena azygos and terminated in the superior vena cava.

Embryogenesis of such an anomaly suggests persistence on the left of one of the longitudinal channels (supra cardinal or subcardinal veins) which normally disappear in early fetal life. Inter post cardinal anastomosis remains persistent in this case as interiliac venous channel.

Caval malformations are considered as a new etiologic factor for thrombosis because of venous stasis. Double Inferior Vena Cava is mostly diagnosed accidently while doing radiographic imaging for other reasons. These type of anomalies if thrombosed can be mistaken as pathological lesions such as Lymphadenopathy, Left pyelo-ureteric dilatation or Metastatic testicular carcinoma. Thus knowledge of such anomalies are of immense importance to surgeons and radiologists to avoid complications during surgeries and diagnostic pitfalls during imaging.

KEY WORDS: Inferior vena cava, duplication of IVC, Azygos vein,

INTRODUCTION: Embryogenesis of Inferior Vena Cava (IVC) is a complex process involving sequential formation and regression of three paired cardinal channels and various anastomosis formed between them at $6^{\text {th }}-8^{\text {th }}$ week of intrauterine life. This complexity accounts for great diversity in anomalies. Duplication of IVC is the most common anomaly $(0.2-3 \%)^{1}$ observed during cadaveric dissection as well as in clinical practice. Various forms of duplication have been reported. Duplication of inferior vena cava with left IVC terminating into left renal vein ${ }^{2}$, Duplication of IVC with azygos continuation ${ }^{3}$, Double IVC with double superior vena cava4, Right sided duplicated IVC5, Duplicated IVC with unilateral retrocaval ureter ${ }^{6}$,or Bilateral retrocaval ureter ${ }^{7}$.

Kehagias et al (1986) $)^{8}$, Muecke et al $(1972)^{9}$, Hama Y (2007) ${ }^{10}$, Mani et al (2000) ${ }^{11}$ have reported association of duplication of IVC with various congenital anomalies. Minniti et al. (2002)12 has reported three new variants of anomalies of IVC. One of which is duplication of IVC with hemiazygos or azygos continuation of left one. Such a rare variant was also observed by us. In this case report, its embryogenesis and clinical importance are discussed. 
OBSERVATION: During routine dissection of middle aged male cadaver an unusual duplication of inferior vena cava was observed. While doing dissection of thorax an Azygos vein about $1 \mathrm{~cm}$ diameter was noticed (Fig-1). This azygos vein, left to abdominal aorta was coming through the aortic opening of the diaphragm.2nd 3rd and 4th intercostals veins of either side joined to form a right and a left superior inter costal vein which opened in the vena azygos. Thorax was then removed from the abdomen at the level of 7 th thoracic vertebra.Accessory hemiazygos vein was absent. Now the dissectionof abdomen was started. Anterior abdominal wall and various abdominal organs were dissected. During dissection of posterior abdominal wall right and left IVC (Fig2) were seen on either side of aorta. Both IVC had their origin from transversely placed interiliac venous channel (about 1 inch in length) in front of 4th lumbar vertebra and about 1 inch below the bifurcation of Abdominal Aorta (at the level of third lumbar vertebra). This venous channel was formed by union of common iliac veins of either side (Fig 2). Right IVC followed its normal course to the right atrium. Left Inferior vena cava, lying on left of lower thoracic vertebra ascended along with aorta on its right side to pass through the aortic opening of diaphragm. In the thorax, it obliquely crossed behind the thoracic part of aorta, from left to right side opposite the 7 th thoracic vertebral body. It behaved like hemiazygos vein and then ascended as vena azygos about $1 \mathrm{~cm}$ in diameter, arching over hilus of right lung and terminated in superior vena cava. Hemiazygos vein was absent. 5th-11th intercostals were terminating in azygos vein. Ascending lumbar veins on either side received lumbar and subcostal veins of their corresponding side and terminated in the azygos vein. In addition to above described venous channel there was an oblique venous channel superficial to the right common iliac artery connecting interiliac venous channel inferiorly and right inferior vena cava superiorly at the level of 2 nd lumbar vertebra. Right and left renal veins were seen terminating into right and left IVC respectively.

Right gonadal and right suprarenal vein terminated in right IVC while left gonadal and left suprarenal vein terminated in the left renal vein.

Two renal arteries close to each other were seen entering the hilum of the right kidney. On left side the two renal arteries were seen crossing left IVC anteriorly. The accessory renal artery on left was originating below the origin of inferior mesenteric artery and after ascending supero laterally to left IVC entered the lowest part of the hilum of the left kidney.

DISCUSSION: Developmentally the inferior vena cava of the adult is a composite vessel. Function of Inferior vena cava is initially carried by right and left postcardinal veins .The early postcardinal veins communicate across the midline via an inter-postcardinal anastomosis. It diverts an increasing volume of blood into right longitudinal veins, which accounts for disappearance of most of those on the left. Numerous anomalies of the Inferior vena cava have been recorded and are attributable to arrests or errors in the complicated series of developmental changes which results in its formation. Sometimes the vessel is represented below the level of renal veins by two more or less symmetrical vessels. This is often associated with absence of the cross anastomosis connecting the two common iliac veins, and is due to persistence on the left of one of the longitudinal channels (supra or subcardinal) which normally disappear in early fetal life. ${ }^{13}$ Inter-postcardinal anastomosis remains persistent in this case as interiliac venous channel and its left end continued with left supracardinal vein(Left Inferior Vena Cava). Prerenal and Postrenal part of Left Subcardinal vein persists as Left suprarenal vein and left gonadal vein, hence terminating in left renal vein. The Left Supracardinal 
vein then continued through hemiazygos vein and with azygos vein which opened in the superior vena cava.

Anomalies of IVC though rare (4\%) ${ }^{14}$ are of immense clinical importance. Etiology of venous thromboembolism in young patients is frequently associated with hereditary coagulation abnormalities, immunological disease and neoplasia. The advent of radiological advances, namely Computed Tomography and venography has identified vena caval malformations as a new etiologic factor worthy of consideration ${ }^{15}$ because of venous stasis ${ }^{16}$. Recurrence of thromboembolism after filter placements or after withdrawal of treatment should raise suspicion of vena caval anomalies. ${ }^{17}$ Radiologically presence of thrombosed double IVC can be mistaken as a pathological lesion such as paraaortic lymphadenopathy ${ }^{14}$ or left pyelo-ureteric dilatation ${ }^{18}$. There are case reports describing patients who underwent exploration for presumed metastatic testicular carcinoma based on CT appearance of the anomaly ${ }^{19}$ as thrombosed double inferior vena cava can mimics paraaortic lymphadenopathy on CT scans raising suspicion of local or distant malignancy. Klimberg et al ${ }^{19}$, Hunter ${ }^{20}$ have reported that error in staging of testicular tumours can be due. A dilated azygos vein may present as widening of mediastinum suggesting a mediastinal mass ${ }^{21}$ or dissection of aorta ${ }^{22}$ on radiographs. Pallin et al (1989) ${ }^{23}$ have reported azygos continuation masquerading as neoplasm.

Vijayvergiya et al (2005)24 have emphasized on knowledge of venous anomalies as it can avoid undue delay during cardiac pacing procedures. Shindo et al $(2000)^{25}$ have reported that unexpected venous injuries complicated the operation in a patient who had a double IVC and inflammatory aortic aneurysm. Preoperative assessment and intraoperative awareness of caval anomalies are important to prevent unexpected venous injuries.

So knowledge of venous anomalies is of immense importance for surgeons as well as for radiologists as it reduces the chances of error in diagnosis and management.

\section{REFERENCES:}

1. Royal S A and Callen P W. CT evaluation of anomalies of inferior vena cava and left renal vein. AJR 1979; (132): 759-763.

2. Kumar S. Anomaly of Inferior vena cava a rare case report. Kathmandu University Medical Journal. 2006; 4(14): 253-255.

3. Tohno Y, Tohno S, Kosugi S, Kuratini S, Kobayashi N, Sakamoto Y. Anomalous Inferior vena cava with azygos continuation in a Japanese man. Anat Sci. Int. 2007 March; 82 (1): 59-61.

4. Mellusco C, Raffla S, Dibella G, Tripoelo E. Double superior and inferior vena cava J. Cardiovasc Med. 2008; 9 (3): 289-92.

5. Nagashima T, Lee J, Andohk, Itoh T, Tanahata K, Arai M, Inoue T. Right double inferior vena cava - Report of 5 cases and literature review. J. Comput Assist Tomog. 2006 Jul - Aug; 30 (4): 642-5.

6. Kokuba T, Okada Y, Yashiro N, Itai Y, CT diagnosis of retrocaval ureter associated with double inferior vena cava: report of a case. Radiat Med. 1990 May. June; 8(3): 96-8.

7. Chou CT, Yang AD, Hong YC, Wu HK. Bilateral retrocaval ureter with IVC duplication. Abdom Imaging 2006 Sept; 31 (5): 596-7.

8. Kehagias DT, Gouliamos AD, Vlhaos LJ. Horse shoe shaped kidney associated with anomalous inferior vena cava. European Radiology 1999; 9(5): 935-6. 
9. Muecke EC, Cook GT, Marshall VF. Duplication of abdominal vena cava associated with cloacalexstrophy. J. Urol 1972; (107): 490-7.

10. Hama Y. Inferior vena cava duplication and left renal aplasia. BJR 2007 (80): e88-e92.

11. Mani N, Venkatramu NK, Singh P, Suri S. Duplication of inferior vena cava and associated renal anomalies. Indian J. Radiol. Imaging 2000; (10): 57-8.

12. Minniti S, Visentini S, Procacci C. Congenital anomalies of venae cavae, embryological origin, imaging features and report of three new variants. Eur Radiol 2002; (12): 2040-55.

13. Standring S Gray's Anatomy. The Anatomical Basis of Clinical Practice. Development of cardiovascular and lymphatic systems 39th Edition Section 6- Thorax, Chapter 61. Elsevier Churchill Livingstone: Edinburgh, London. 2006, pp-1049.

14. Evans JC, Earis J, Curtis J. Thrombosed double inferior vena cava mimicking paraaortic lymphadenopathy. Br. J. Radiol. 2001 Feb; 74 (878): 192-194.

15. Milani C, Constantinou M, Berz D, Butera JN, Colvin GA. Left sided inferior vena cava duplication and venous thromboembolism: case report and review of literature. Journal of Hematology and Oncology. 2008.1:2

16. Obernosterer A, Aschauer M. Mitterhammer H, Lipp RW. Congenital familial vascular anomalies, a study of patients with an anomalous inferior vena cava and of their $1^{\text {st }}$ degree relatives. Angiology 2004 Jan-Feb; 55 (1): 73-7.

17. Fuster MJG, Forner MJ, Flor. Lorente B, Campos JSYS Inferior Vena Cava Malformations and Deep vein Thrombosis Rev Esp Cardio 2006; 59 (02): 171-

18. Gay SB, Armistead JP, Weber ME, Williamson BR. Left infrarenal region; anatomic variants, pathological conditions, and diagnostic pitfalls. Radiographics 1991:11; 549-70

19. Klimberg I, Waysman Z. Duplicated IVC simulating retroperitoneal lymphadenopathy in a patient with embryonal cell carcinoma of testicle. J. Urol. 1986; 136(3): 678-9.

20. Hunter JD Double and nothing. BJR 1998; (71):99.

21. Gayer G, Luboschitz J, Hertz M, Zissin R, Thaler M, Lubetsky A, Bass A, Korat A and Apter S. Congenital Anomalies of inferior vena cava revealed on CT in patients with deep vein thrombosis. Journal of Roentgenology 2003; (180): 729-732.

22. Evan AJ: Case report: Azygos / accessory hemiazygos continuation of inferior vena cava mimicking dissection of aorta. Clinical Radiology 1993 Sept; 48 (3): 207-9.

23. Pallin J, Buckner CB, Ferris EJ, Shah HR, Jones JS. Azygos continuation of inferior vena cava masquerading as neoplasm. South Med J. 1989 Feb; 82 (2): 259-61.

24. Vijay Vergiya R, Bhat MN, Kumar RM, Vivekanand SG. Azygos continuation of interrupted inferior vena cava in association with sick sinus syndrome Heart 2005; 91 (4):

25. Shindo S, Kubota K, Kojima A, Iyori K, Ishimoto T, Kobayashi M, Kaniya K, Tada Y. Anomalies of inferior vena cava and left renal vein. Risks in Aortic surgery. Annals of vascular surgery 2000; (14): 393-396. 


\section{CASE REPORT}

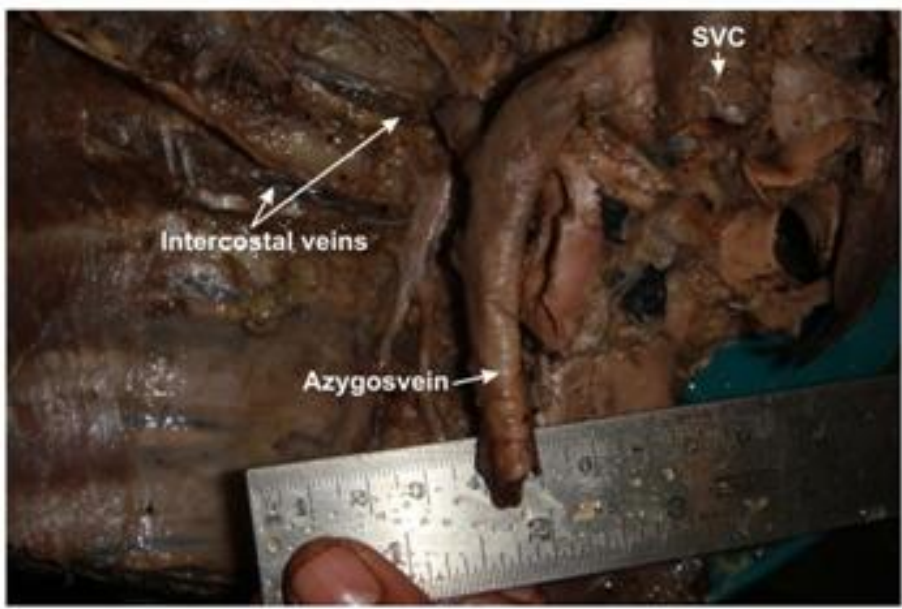

Fig. 1 Dilated azygos Vein (Continuation of Left IVC) terminating in superior vena cava (SVC)

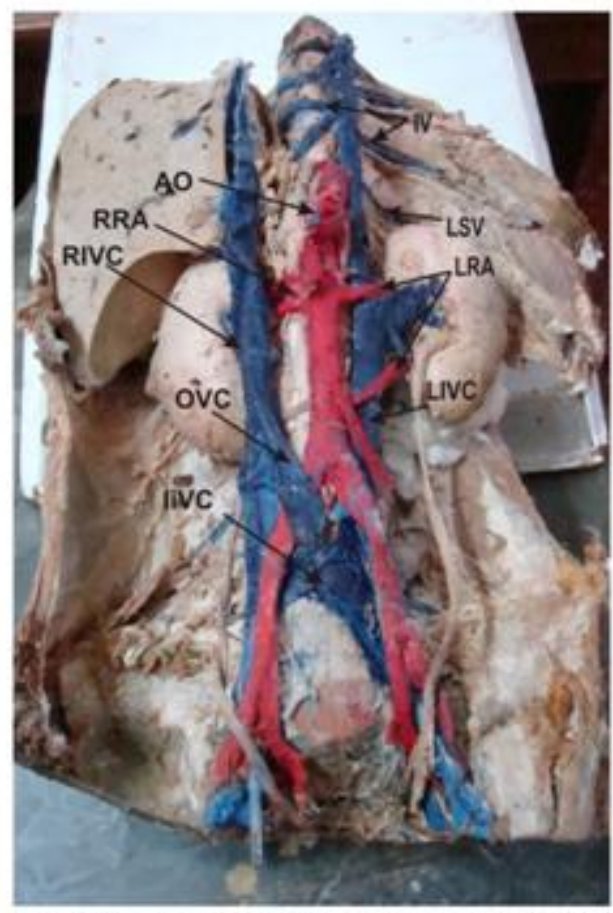

Fig. 2 Double Inferior Vena Cava and Left IVC Continuing as Azygos Vein
AO : Abdominal Aorta
N : Intercostal Veins
RRA : Right Renal Arteries
LSV : Left Subcostal Vein
RIV : Right Inferior Vena Cava
LRA : Left Renal Arteries
OvC : Oblique Venous Channel
UNC : Left Inferior Vena Cava
IVC : Interliac venous channe 


\section{AUTHORS:}

1. Parveen Ojha

2. Seema Prakash

3. L.K. Jain

\section{PARTICULARS OF CONTRIBUTORS:}

1. Assistant Professor, Department of Anatomy, R.N.T. Medical College, Udaipur.

2. Associate Professor, Department of Anatomy, R.N.T. Medical College, Udaipur.

3. Professor, Department of Anatomy, Geetanjali. Medical College \& Hospital, Udaipur.
NAME ADRRESS EMAIL ID OF THE CORRESPONDING AUTHOR:

Dr. Parveen Ojha,

D-17, Hospital Campus,

M.B. Govt. Hospital,

Udaipur, (Rajasthan)

Email: drparveena@yahoo.com

Date of Submission: 26/06/2013.

Date of Peer Review: 27/06/2013.

Date of Acceptance: 13/07/2013.

Date of Publishing: 17/07/2013 